\author{
Marquette University \\ e-Publications@Marquette
}

School of Dentistry Faculty Research and

Publications

Dentistry, School of

2017

\title{
Expression of Interleukin-1 and Temporomandibular Disorder: Contemporary Review of the Literature
}

\author{
Adam Sorenson \\ Marquette University \\ Kyle Hresko \\ Marquette University \\ Seth Butcher \\ Marquette University \\ Sean Pierce \\ University of California - Los Angeles \\ Vinícius Augusto Tramontina \\ Pontifical University of Paraná
}

See next page for additional authors

Follow this and additional works at: https://epublications.marquette.edu/dentistry_fac

Part of the Dentistry Commons

\section{Recommended Citation}

Sorenson, Adam; Hresko, Kyle; Butcher, Seth; Pierce, Sean; Tramontina, Vinícius Augusto; Leonardi, Rosalia; Loreto, Carla; Bosio, Jose A.; and Almeida, Luis Eduardo, "Expression of Interleukin-1 and Temporomandibular Disorder: Contemporary Review of the Literature" (2017). School of Dentistry Faculty Research and Publications. 297.

https://epublications.marquette.edu/dentistry_fac/297 


\section{Authors}

Adam Sorenson, Kyle Hresko, Seth Butcher, Sean Pierce, Vinícius Augusto Tramontina, Rosalia Leonardi, Carla Loreto, Jose A. Bosio, and Luis Eduardo Almeida 
Marquette University

\section{e-Publications@Marquette}

\section{Dentistry Faculty Research and Publications/School of Dentistry}

This paper is NOT THE PUBLISHED VERSION; but the author's final, peer-reviewed manuscript. The published version may be accessed by following the link in the citation below.

CRANIO $^{\circledR}$ : The Journal of Craniomandibular \& Sleep Practice, (2017). DOI. This article is (C) Taylor $\&$ Francis and permission has been granted for this version to appear in e-

Publications@Marquette. Taylor \& Francis does not grant permission for this article to be further copied/distributed or hosted elsewhere without the express permission from Taylor \& Francis.

\section{Expression of Interleukin-1 and Temporomandibular Disorder: Contemporary Review of the Literature}

\section{Adam Sorenson}

Surgical Sciences Department, Oral Surgery, School of Dentistry, Marquette University, Milwaukee, WI

Kyle Hresko

Surgical Sciences Department, Oral Surgery, School of Dentistry, Marquette University, Milwaukee, WI

Seth Butcher

Surgical Sciences Department, Oral Surgery, School of Dentistry, Marquette University, Milwaukee, WI

Sean Pierce OMFS Department, School of Dentistry, University of California, Los Angeles, Los Angeles, CA Vinicius Tramontina Periodontic Department, School of Dentistry, Pontifica Universidade Catolica do Parana, Brazil Rosalia Leonardi 
Orthodontic Department, School of Dentistry, Catania University, Italy

\section{Carla Loreto}

Anatomy Department, School of Medicine, Catania University, Italy

Jose Bosio

Orthodontic Department, School of Dentistry, University of Maryland, Baltimore, MD

Luis Eduardo Almeida

Surgical Sciences Department, Oral Surgery, School of Dentistry, Marquette University, Milwaukee, WI

\section{Abstract}

Objective: Temporomandibular disorders (TMD) are a group of conditions affecting the temporomandibular joint (TMJ), leading to jaw dysfunction, joint and muscle pain, and a decrease in quality of life. A communication network of pro- and anti-inflammatory mediators called cytokines maintains the homeostasis of the TMJ. This review will focus on the Interleukin (IL) family of cytokines, which have been quantified in TMJ synovial fluids in a variety of studies. IL- $1 \alpha$ and IL-1 $\beta$ have proinflammatory effects, while the endogenous receptor antagonist (IL-1RA) inhibits the pro-inflammatory effects of IL-1.

Methods: A literature search (2006-2016) to identify eligible studies was completed using the PubMed database. Studies identified used saline irrigation to quantify cytokine profiles in synovial fluid of healthy and/or dysfunctional joints.

Results: The initial search yielded 111 articles, 5 of which met the inclusion criteria after inter-reviewer discussion.

Conclusions: Articles that compared IL-1 concentrations in TMD vs. control groups found significant differences.

Keywords: Temporomandibular joint, Interleukin-1, temporomandibular joint disorder

\section{Introduction}

The temporomandibular joint (TMJ) is one of the most complex articulations in the human body. The TMJ is an intricate joint that is made up of the joint itself, the masticatory muscles, cartilaginous tissue, and bone. Temporomandibular disorders (TMD) are a group of conditions affecting the TMJ. These disorders lead to jaw dysfunction, joint and muscle pain, and a decrease in overall quality of life. 1 There is a variable disease progression from mild inflammatory responses to complete architectural changes of the TMJ. Along with the different stages of TMD, there are different signs and symptoms that accompany each stage. This is the result of adaptation and remodeling of the TMJ. When the disc is overloaded and it exceeds its remodeling capacity, it may suffer structural changes. The pathogenesis of TMD is multifactorial, but the early identification of the major contributing factor is critical for improved treatment outcomes. Of the TMJ dysfunctions that may lead to disc degeneration, disc displacement is generally seen to precede osseous remodeling, disc perforation and osteoarthritic changes. $\underline{\underline{?}}$

The TMJ is subjected to constant stress, due to significant forces exerted during function. Because of this, constant remodeling of the joint is necessary with simultaneous metabolism and repair. Excessive loading on the TMJ is generally considered an initiating pathogenesis of TMD. This constant remodeling is the result of a dynamic and extremely complex communication between the cells that make up the 
TMJ, specifically the cells of the synovial joint, the articular disc, and the condylar cartilage. $\underline{3}$ Homeostasis of the TMJ is maintained through a complex network of cellular molecules, such as cytokines, proteinases, and other inflammatory mediators. These regulatory molecules affect the metabolism of the extracellular matrix by altering gene and protein expression. There have been wide arrays of cellular markers studied in TMD. These include inflammatory mediators such as the Interleukin family, matrix metallo-proteinases, bone-destruction associated cytokines, apoptotic mediators, and anti-inflammatory cytokines. $\stackrel{4}{\text { Most }}$ of these studies have found correlations between a specific homeostasis mediator and a stage in TMD development. Unfortunately, due to the nature of the TMJ and current treatment, most studies have been limited to synovial fluid examination of these markers. Thus, a more complete marker profile is needed to gain a better understanding of the pathology of TMD.

Cytokine is a general name for small proteins produced and released by cells for communication. Cytokines are responsible for initiating, maintaining, and halting inflammatory processes. As such, there is a wide array of cytokine families that are responsible for different functions in different areas of the

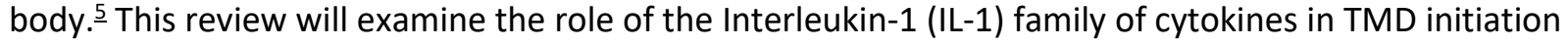
and progression.

The most numerous and complex family of cytokines is the Interleukins. ${ }^{6}$ A great amount of effort has been spent on mapping out and understanding the interactions of the Interleukin network. Within this family, there are both pro-inflammatory and anti-inflammatory mediators. The prevalence of specific Interleukins varies, and this correlates to their degree of influence on cellular activity. Their subsequent expression triggers a cascade of events, and IL-1 is the prime example of this.

The IL-1 system includes at least 21 different molecules. These molecules make up the IL-1 receptors, co-receptors, ligands and endogenous antagonists. The IL-1 family consists of three types of ligands: IL$1 \alpha$ and IL-1 $\beta$ both have pro-inflammatory effects, while IL-1 receptor antagonist (IL-1RA) inhibits their pro-inflammatory functions by acting as a competitive receptor inhibitor. There are also two different receptors that make up the IL-1 family, Type 1 and Type 2 IL-1 receptors. Type 1 IL-1 receptor is responsible for induction of intracellular signal transductions after binding with IL-1. Type 2 IL-1 receptor acts as a decoy receptor. Its function is to bind to IL-1 without producing any effects, thus reducing the overall availability of IL-1 to bind and initiate an inflammatory response. Additionally, Type 2 IL-1 receptor can be released from the cell surface in a soluble form that can bind to IL-1 ligands to inactivate them before they can produce a pro-inflammatory response. $\frac{?}{7}$ The intricate balance of the IL- 1 family molecules and receptors has a profound effect on the homeostasis of the TMJ. Many studies have indicated that higher levels of IL-1 $\alpha$ and IL-1 $\beta$ are present in the synovial fluid of patients suffering from TMD.., 9 These studies have taken synovial fluid samples from patients suffering from TMD at different stages. Conclusions have been made suggesting that elevated levels of these cytokines contribute to the initiation and progression of TMD.

In normal, healthy TMJ discs, there are virtually no pro-inflammatory cytokines present. $\stackrel{9}{ }$ Soon after TMJ discs are subjected to excessive loads and function, they begin to undergo pathologic changes. These mechanical disturbances produce an imbalance between anabolic and catabolic processes, which progressively alters TMJ disc tissue. $\frac{10}{}$ Damage of the TMJ disc is associated with excessive catabolic activity that results from cytokines and proteases. IL-1 is one of the most prevalent and first cytokines produced as a response to excessive loading of the TMJ. $\underline{11}$ The release of IL- 1 initiates a cascade of events that ultimately leads to tissue alteration. This cascade alters the extracellular matrix by depleting matrix substances such as collagen. 
Although the role of IL-1 in inflammation and TMJ dysfunction is well known, previous studies have investigated the presence of IL-1 in animal models, cadavers, or synovial fluid of humans. The goal of this review is to examine IL-1 levels in human synovial fluid and disc studies that compare healthy and diseased TMJs.

\section{Materials and methods}

\section{Search strategy}

Two reviewers conducted an electronic literature search using the PubMed database. Inclusion criteria were articles written in English published in the last 10 years (2006-2016) with human subjects. The following search strategies were used:

1. "Osteoarthritis" [MeSH Terms] OR "arthritis, rheumatoid" [MeSH

Terms] AND "temporomandibular joint disorders" [MeSH Terms] OR"temporomandibular joint" [MeSH Terms] AND “Interleukin-1" [MeSH Terms] AND "2006/05/18" [PDat] : "2016/05/14" [PDat] AND "humans" [MeSH Terms]

2. "Temporomandibular joint disorders" [MeSH Terms] OR"temporomandibular" [All Fields] AND "physiopathology" [Subheading] OR "joints" [All Fields] OR "joint" [All Fields] AND "temporomandibular" [All Fields] OR "degeneration" [All Fields] AND "temporomandibular" [All Fields] OR "temporomandibular joint" [MeSH Terms] AND“Interleukin-1" [MeSH Terms]

Reviewers independently removed duplicates and screened titles. Inclusion and exclusion criteria were applied during an independent abstract analysis. Inter-reviewer discussion completed the selection process.

\section{Selection criteria}

Eligible studies met the following inclusion criteria:

1. Studies evaluating IL-1 presence or concentration in synovial fluid or discs of dysfunctional and/or healthy TMJs

2. Articles written in English

3. Human studies

4. Publications in the last ten years (2006-2016)

Exclusion criteria included:

1. Case reports

2. Pilot studies

3. Literature reviews

Data analysis

Study designs and parameters varied greatly; thus data analysis was not practical. Some studies directly compared cytokine profiles in healthy and dysfunctional joints. Others quantified cytokines solely in healthy or diseased joints. The following parameters were gathered from the selected articles: author/year of publication, sample studied, mean age of subjects, Interleukins evaluated, method of TMJ assessment, and a summary of the results (Table 1). All studies utilized immunoassay for the Interleukin assessment. This paper will discuss results pertaining to IL-1, though selected articles examined additional Interleukins. 
Table 1. Researchers' characteristics and main results.

\begin{tabular}{|c|c|c|c|c|c|}
\hline Author/year & Sample & $\begin{array}{c}\text { Age } \\
\text { (mean) }\end{array}$ & Interleukin & TMJ assessment & Results \\
\hline $\begin{array}{l}\text { Ahmed et al., } \\
2014\end{array}$ & $\begin{array}{l}\text { G1: } 22 \text { rheumatoid arthritis patients with or } \\
\text { without TMD }\end{array}$ & Unreported & IL-1ra, IL-1sRII & $\begin{array}{l}\text { MRI, clinical signs } \\
\text { and symptoms }\end{array}$ & $\begin{array}{l}\text { High IL-1ra levels in relation to TNF in TMJ synovial fluid } \\
\text { correlated to greater degrees of condylar erosion }\end{array}$ \\
\hline \multirow{3}{*}{$\begin{array}{l}\text { Hamada et } \\
\text { al., } 2006\end{array}$} & \multirow{2}{*}{$\begin{array}{l}\text { G1: successful (s-), clinical success after joint } \\
\text { irrigation (25 patients) }\end{array}$} & \multirow[t]{2}{*}{46.5} & \multirow[t]{2}{*}{$\mathrm{IL}-1 \beta, \mathrm{IL}-6, \mathrm{IL}-8, \mathrm{IL}-12 \mathrm{p} 70, \mathrm{IL}-10$} & \multirow{2}{*}{$\begin{array}{l}\text { MRI, clinical signs } \\
\text { and symptoms }\end{array}$} & IL-6: $G 2>G 1$ \\
\hline & & & & & IL-10: $\mathrm{G} 1>\mathrm{G} 2$ \\
\hline & $\begin{array}{l}\text { G2: unsuccessful (u-), no clinical success after } \\
\text { joint irrigation (11 patients) }\end{array}$ & & & & IL-1: no significant differences \\
\hline \multirow[t]{2}{*}{$\begin{array}{c}\text { Kim et al., } \\
2012 \\
\end{array}$} & G1: TMD group (22 patients) & 26.9 & IL-1 $1 \beta$, IL-2, IL-4, IL-5, IL-6, IL-8, IL-10 & $\begin{array}{l}\text { MRI, clinical signs } \\
\text { and symptoms }\end{array}$ & IL-1 $\beta$, IL-2, IL-6, IL-8, IL-10: G1>G2 \\
\hline & G2: normal group (control, 33 patients) & & & & \\
\hline $\begin{array}{l}\text { Kristensen et } \\
\text { al., } 2014\end{array}$ & G1: 20 healthy young adults without TMD & 23 & $\mathrm{IL}-1 \beta, \mathrm{IL}-2, \mathrm{IL}-6, \mathrm{IL}-10$, & $\begin{array}{l}\text { Clinical signs and } \\
\text { symptoms }\end{array}$ & IL-10, IL-1 $1 \beta$, and IL- 6 were mostly undetectable \\
\hline $\begin{array}{l}\text { Matsumoto et } \\
\text { al., } 2006\end{array}$ & $\begin{array}{c}\text { G1: } 14 \text { patients with internal derangement of } \\
\text { TMJs }\end{array}$ & 41.1 & $\begin{array}{l}\mathrm{IL}-10, \mathrm{IL}-1 \beta, \mathrm{IL}-2, \mathrm{IL}-3, \mathrm{IL}-4, \mathrm{IL}-5, \mathrm{IL}- \\
6, \mathrm{IL}-7, \mathrm{IL}-8, \mathrm{IL}-10, \mathrm{IL}-12\end{array}$ & $\begin{array}{l}\text { MRI, Clinical signs } \\
\text { and symptoms }\end{array}$ & $\begin{array}{l}\text { No single cytokine was positive in all samples. IL-10 showed most } \\
\text { abundant expression }\end{array}$ \\
\hline
\end{tabular}

\section{Results}

\section{General outcomes}

The initial electronic search returned 111 records. Exclusion criteria were publications older than 10 years, non-human studies, and articles that did not compare IL-1 expression levels in a disease group and control. Inter-reviewer discussion resulted in the exclusion of 106 articles. Five articles remained in this review. Statistical analysis was not completed due to differing parameters, variables, and study designs.

\section{Description of the studies}

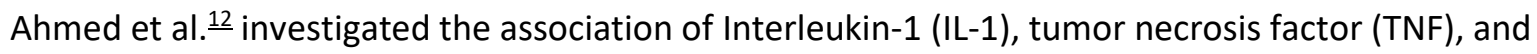
autoantibodies to citrullinated proteins (ACPA) with radiological signs of TMJ disc displacement and tissue resorption in rheumatoid arthritis (RA) patients. Twenty-two RA patients were included, regardless of whether they had TMJ symptoms. TMJ synovial fluid was analyzed for the ratios of the cytokines and their endogenous control mediators after saline washing of the joint. Magnetic resonance imaging (MRI) of disc position was interpreted and presence of erosions and joints were grouped into five categories: (1) normal, (2) disc displacement with reduction, (3) disc displacement without reduction, (4) indeterminate, and (5) disc not visible. Venous blood was collected for analysis. High IL1RA levels in relation to TNF in TMJ synovial fluid correlated to greater degrees of condylar erosion.

Hamada et al. $\underline{13}$ examined concentrations of TNF- $\alpha$, IL-1 $\beta$, IL-6, IL-8, IL-12, and IL-10 in the irrigated synovial fluid of patients with chronic closed lock (CCL) of the TMJ. Clinical outcome of the irrigation was correlated to cytokine concentrations. Thirty-eight patients with $\mathrm{CCL}$ of the TMJ underwent saline irrigation of the superior joint compartment. Patients were divided into successful (s-) or unsuccessful (u-) groups according to clinical success. Concentrations of IL-6 were significantly higher in the u-group, and concentrations of IL-10 were significantly higher in the s- group. No significant differences in detection and concentration were observed among the other cytokines tested, including IL-1.

Kim et al. $\underline{14}$ compared cytokine profiles of TMJ synovial fluid of normal individuals and TMD patients. Thirty-three TMJ patients were assigned to the control group and 22 patients seeking treatment for TMD were assigned to the TMD group. Saline irrigation with synovial fluid collection was performed. Concentrations of GM-CSF, INF- $\gamma$, IL-1 $\beta$, IL-2, IL-4, IL-5, IL-6, IL-8, IL-10, and TNF- $\alpha$ were measured. GMCSF, INF- $\gamma$, IL-1 $\beta$, IL-2, IL-6, IL-8, IL-10 and TNF- $\alpha$ were detected in the TMD group. No cytokines were detected in the control group. IL-1 $1 \beta, \mathrm{IL}-6$, and GM-CSF were the most frequently found cytokines in the TMD group. The authors concluded that there were significant differences in detection of the cytokines with a higher level of IL-1 $\beta$ in the TMD group vs. the control group. 
Kristensen et al. $\underline{15}$ quantified the proinflammatory cytokines IL-1 $\beta$, IL-2, IL-6, TNF, and IFN- $\gamma$ in healthy TMJ synovial fluid for comparison to TMJ pathologies. Twenty healthy, young participants were chosen with no history of temporomandibular disease or dysfunction. Synovial fluid was collected from the superior TMJ compartment bilaterally. Cytokines were quantified in 14 of the samples collected. Median cytokine values in pg ML-1 were: TNF, 23; IL-2, 1.8; INF- $\gamma, 10, \mathrm{IL}-1 \beta, \mathrm{IL}-6$, and IL-10 were considered undetectable. A significant correlation was noted between TNF and IFN- $\gamma$ concentrations.

Matsumodo et al. $\underline{16}$ developed a comprehensive cytokine profile of 14 patients with TMD and correlated the levels with radiological findings. No control group participated. Participants had verified anterior disc displacements without reduction. Synovial fluid was collected and analyzed using Human Cytokine Array V. No single cytokine was positive in all samples, but those present most abundantly were IL- $1 \alpha$, TGF- $\beta 2$, and VEGF.

\section{Discussion}

Studies differed in their designs, subject groups, and variables measured. Two of the five studies selected (Ahmed, Kim) directly compared cytokine concentrations in both groups of TMD patients and healthy controls. Both studies found significant differences in cytokine profiles, with Ahmed et al. finding high IL-1RA levels correlating to greater degrees of condylar erosion and Kim et al. finding a higher level of IL-1 $\beta$ in the TMD group. $\frac{12,14}{2}$ Hamada et al. quantified cytokines during saline irrigation as a treatment for CCL of the TMJ, then divided subjects into groups based on clinical success. Though differences were noted in other Interleukins, no significant differences in detection and concentration were noted for IL$1 . \underline{13}$ The two remaining studies lacked control groups. Kristensen et al. looked solely at cytokine concentrations in healthy TMJ synovial fluid and noted IL-1 $\beta$ was undetectable. $\frac{15}{n}$ Matsumodo et al. examined cytokine profiles of patients with TMD and found IL-1 $\alpha$ to be abundantly expressed. $\underline{16}$

Despite largely differing study designs, conclusions can be made regarding the association of IL-1 with temporomandibular dysfunction. The IL-1 family of cytokines, including IL-1 $\alpha$, IL-1 $\beta$, and IL-1RA, was generally found in higher concentrations in the synovial fluid of dysfunctional joints. $12,14,16$

Limitations exist in the studies selected for this review. Study samples were small, ranging from 14 to 55 patients and were limited to synovial fluid. Natiella et al. $\underline{\text {. }}$ emphasized that correlation of synovial fluid aspirates with tissue findings is necessary for a more complete understanding of joint biochemistry. Therefore, more reliable data would be obtained from cytokine studies of both joint aspirates and disc samples.

A recent study by Almeida et al. $\underline{18}$ was the first to use an immunohistochemical approach to quantify IL$1 \beta$ in human TMJ disc samples. The study concluded that IL-1 $\beta$ plays a role in the process leading to $T M D$, citing a statistically significant difference between study groups. These results correlate with synovial fluid aspirate findings in the studies selected in this review. Therefore, IL-1 $\beta$ can be found in both the synovial fluid and the articular disc of the TMJ.

\section{Conclusion}

Continued synovial fluid and disc tissue studies of additional IL-1 family cytokines as well as other markers will provide a more reliable and complete profile of inflammatory contributors to TMD. This may ultimately provide a positive contribution to the future of TMD therapy. Knowledge of the markers involved in inflammation and destruction of the TMJ opens possibilities for more targeted therapy. 
Pharmaceutical blockade of IL-1 activity has been used to successfully treat joint, bone, and muscle diseases such as rheumatoid arthritis, erosive osteoarthritis, and traumatic joint injuries [19]. Specific targeting of pathologic mediators, including the IL-1 family of cytokines, may significantly reduce inflammation and prevent further degeneration of the TMJ.

\section{References}

1. Wang XD, Zhang JN, Gan YH, et al. Current understanding of pathogenesis and treatment of TMJ osteoarthrosis. J Dent Res. 2015;94(5):666-673.10.1177/0022034515574770

2. Almeida LE, Caporal K, Ambros V, et al. Immunohistochemical expression of matrix metalloprotease-2 and matrix metalloprotease- 9 in the disks of patients with temporomandibular dysfunction. J Oral Pathol Med. 2015;44:75-79.10.1111/jop.2014.44.issue1

3. Herrero-Beaumont G, Roman-Blas JA, Casandea S, et al. Primary osteoarthritis no longer primary: three subsets with distinct etiological, clinical, and therapeutic characteristics. Semin Arthritis Rheum. 2009;39(2):71-80.10.1016/j.semarthrit.2009.03.006

4. Vernal R, Velasquez E, Gamonal J, et al. Expression of proinflammatory cytokines in osteoarthritis of the temporomandibular joint. Arch Oral Biol. 2008;53:910915.10.1016/j.archoralbio.2008.04.004

5. Alstergren $P$, Benavente $C$, Kopp $S$. Interleukin-1 $\beta$, interleukin-1 receptor antagonist, and interleukin-1 soluble receptor II in temporomandibular joint synovial fluid from patients with chronic polyarthritides. J Oral Maxillofac Surg. 2003;61:1171-1178.10.1016/S02782391(03)00678-5

6. Peters VA, Joesting JJ, Freund GG. IL-1 receptor 2 (IL-1R2) and its role in immune regulation. Brain Behav Immun. 2013;32:1-8.10.1016/j.bbi.2012.11.006

7. Tominaga K, Habu M, Sukedai M, et al. IL-1ß, IL-1 receptor antagonist and soluble type II IL-1 receptor in synovial fluid of patients with temporomandibular disorders. Arch Oral Biol. 2004;49:493-499.10.1016/j.archoralbio.2003.12.008

8. Kubota E, Kubota T, Matsumoto J, et al. Synovial fluid cytokines and proteinases as markers of temporomandibular joint disease. J Oral Maxillofac Surg. 1998;56:192-198.10.1016/S02782391(98)90868-0

9. Kristensen $K D$, Alstergren $P$, Stoustrup $P$, et al. Cytokines in healthy temporomandibular joint synovial fluid. J Oral Rehabil. 2014;41:250-256.10.1111/joor.12146

10. Leonardi $R$, Loreto $C$, Barbato $E$, et al. A histochemical survey of the human temporomandibular joint disc of patients with internal derangement without reduction. J Craniofac Surg. 2007;18:1429-1433.10.1097/scs.0b013e31814fb72a

11. Kim YK, Kim SG, Kim BS, et al. Analysis of the cytokine profiles of the synovial fluid in a normal temporomandibular joint: preliminary study. J Craniomaxillofac Surg. 2012;40:337341.10.1016/j.jcms.2012.02.002

12. Ahmed N, Petersson A, Catrina Al, et al. Tumor necrosis factor mediates temporomandibular joint bone tissue resorption in rheumatoid arthritis. Acta Odontol Scand. 2015;73(3):232240.10.3109/00016357.2014.994561

13. Hamada $Y$, Kondoh $T$, Holmlund $A B$, et al. Inflammatory cytokines correlated with clinical outcome of temporomandibular joint irrigation in patients with chronic closed lock. Oral Surg Oral Med Oral Pathol Oral Radiol Endod. 2006;102:596-601.10.1016/j.tripleo.2005.11.010

14. Kim YK, Kim SG, Kim BS, et al. Analysis of the cytokine profiles of the synovial fluid in a normal temporomandibular joint: preliminary study. J Craniomaxillofac Surg. 2012;40:337341.10.1016/j.jcms.2012.02.002 
15. Kristensen KD, Alstergren $P$, Stoustrup $P$, et al. Cytokines in healthy temporomandibular joint synovial fluid. J Oral Rehabil. 2014;41:250-256.10.1111/joor.12146

16. Matsumoto $K$, Honda $K$, Ohshima $M$, et al. Cytokine profile in synovial fluid from patients with internal derangement of the temporomandibular joint: a preliminary study. Dentomaxillofac Radiol. 2006;35(6):432-441.10.1259/dmfr/77288976

17. Natiella JR, Burch L, Fries KM, et al. Analysis of the collagen I and fibronectin of temporomandibular joint synovial fluid and discs. J Oral Maxillofac Surg. 2009;67(1):105113.10.1016/j.joms.2008.08.029

18. Almeida LE, Pierce S, Zacharias J, et al. Immuno-histochemical analysis of IL-1 beta in the discs of patients with temporomandibular joint dysfunction. CRANIO ${ }^{\circledR}$. 2016;13:1-5.

19. Dinarello CA, Simon A, van der Meer JWM. Treating inflammation by blocking interleukin-1 in a broad spectrum of diseases. Nat Rev Drug Discov. 2012;11(8):633-652.10.1038/nrd3800 